OPEN ACCESS

Edited by:

Eleonora Nannoni,

University of Bologna, Italy

Reviewed by:

Patrick Pageat,

Institut de Recherche en Sémiochimie

et Ethologie Appliquée

(IRSEA), France

Hayley Randle,

Charles Sturt University, Australia

*Correspondence:

Oliver Bendel

oliver.bende@@fhnw.ch

Specialty section:

This article was submitted to Animal Welfare and Policy,

a section of the journal

Frontiers in Animal Science

Received: 13 December 2021

Accepted: 21 January 2022

Published: 25 February 2022

Citation:

Bendel O (2022) Passive, Active, and

Proactive Systems and Machines for the Protection and Preservation of

Animals and Animal Species.

Front. Anim. Sci. 3:834634

doi: 10.3389/fanim.2022.834634

\section{Passive, Active, and Proactive Systems and Machines for the Protection and Preservation of Animals and Animal Species}

\author{
Oliver Bendel* \\ Institute for Information Systems, School of Business FHNW, Windisch, Switzerland
}

Digitalization and automation are expanding into many areas, resulting in more widespread use of partially and fully autonomous machines and robots. At the same time, environmental and other crises and disasters are on the rise, the world population is growing, and animals are losing their habitat. Increasingly, machines and robots such as agricultural vehicles, autonomous cars, robotic lawnmowers, or social robots are encountering animals of all kinds. In the process, the latter are injured or killed. Some machines can be designed so that this does not happen. Relevant disciplines and research areas briefly introduced here are machine ethics, social robotics, animal-machine interaction, and animal-computer interaction. In addition, animal welfare is important. Passive and active machines - as they are called in this review-are already appearing and help to observe and protect animals. Proactive machines may play a role in the future. They could use the possibilities of full automation and autonomy to save animals from suffering in agriculture or in the wild. During crises and disasters and in extensive nature reserves, they could observe, care for, and protect animals. The review provides initial considerations on active, passive, and proactive machines and how they can be used in an animal preservation context while bearing in mind recent technical and global developments.

\footnotetext{
Keywords: animal ethics, machine ethics, animal-machine interaction, animal-computer interaction, animal welfare, robotics, artificial intelligence
}

\section{INTRODUCTION}

Digitalization and automation are expanding worldwide. Increasingly, automatic and autonomous systems and machines are emerging, including self-driving cars, service robots, and social robots - not to mention industrial robots, for example in car production, where they were first used in the 1960s. At the same time, fundamental changes, crises, and disasters (both natural and man-made) are increasing, as is the human population, which is building cities and infrastructures everywhere while requiring a seemingly limitless supply of resources. As a result, the habitat of animals is being destroyed, individual animals are killed in this context, and whole animal species (as well as plant species) are becoming extinct. Industrialization, mechanization, and digitalization are one cause of this. However, they can also, to a certain extent, offer solutions. Currently, automatic and (partially) autonomous systems and machines are encountering animals more frequently with little thought by people and companies of how they can do so responsibly. 
The systems and machines at issue in the present context meet animals intentionally or unintentionally, can or cannot distinguish between individuals or species, encounter domestic animals, working animals, farm animals, wild animals, or laboratory animals. They can exploit animals, modify animals, injure and kill animals, or help and spare animals (Bendel, 2014a). They function independently of animals (outside their bodies) or become part of them (inserted into the body in the form of chips and implants, for example in the context of animal enhancement). They can occur in the home, in the garden, in urban areas, in agriculture, or in the open countryside (even in the wilderness), are passive (mainly observing), active (e.g., responding to an animal), or proactive (e.g., interacting and communicating with an animal, or recognizing, caring for, and removing an animal for its safety). This review presents selected examples and distinguishes them according to the classifications presented, particularly focusing on passive, active, and proactive systems and machines. It shows that many existing automatic and (partially) autonomous systems and machines are passive or active in their relationship to animals. This review focuses on how machines and non-human living beings meet and how this can be better designed for the welfare of animals. It is mainly about, on the one hand, how to avoid damage that can be caused by machines by modifying the machines themselves and, on the other hand, how machines can protect and save animals from threats by humans and during natural or man-made crises and disasters. In order to conduct this discussion in a structured manner and to provide suggestions for future developments, the aforementioned systematization was introduced.

An example of a passive system is the use of drones that detect fawns in the field, helping to stop combine harvesters from running them over, or animal-like robots such as those invented by John Downer for animal monitoring as part of his wildlife films (which have been shown on BBC, the national broadcaster of the United Kingdom, for example). Active systems and machines-most of which have a passive componentinclude LADYBIRD from Switzerland, a prototype robot vacuum cleaner that pauses its work when it detects ladybugs, and HAPPY HEDGEHOG, a prototype robotic lawnmower that pauses its work when it encounters hedgehogs. The Wildlife Vehicle Collision Avoidance System developed in India is also of this type. It detects when deer approach the road and warns drivers with light signals. Spain's DTBird not only monitors the flight of birds, but also ensures that wind turbines are stopped when necessary to protect wildlife. In principle, the drones mentioned above could also give a command to an automatic combine harvester, which then interrupts its work, which would make them active rather than passive systems.

This review shows that a variety of passive and active systems and machines already exist, some of which are helpful for the protection and conservation of animal individuals or species. Research areas and disciplines such as animal-computer interaction, animal-machine interaction, machine ethics, and social robotics are all relevant to these. It is suggested that in some cases, and especially in the future, such systems will not be sufficient to account for the growth and spread of humanity and its impact on the earth's environment and ecology. The author argues that proactive systems and machines are needed to protect animals and their habitats in economically viable ways and to save species from extinction. This applies to both urban and agricultural areas, where autonomous systems and machines are proliferating and, for that reason alone, increasingly encountering animals. It applies also to the outdoor nature, by which is meant managed forests and plains as well as the increasingly rare (but perhaps expandable) wilderness.

One proactive solution is to have fully automated systems to protect animals. For example, one may intend rescuing fawns. A drone detects the animal in the field and reports this to the combine harvester, which immediately stops. A robot then picks up the fawn and brings it to safety (in current implementations, this is done by a human helper). Such a solution makes economic sense, for example because of the potential savings in personnel. Currently, however, it is not technically feasible. Another (much broader) vision is of greatly expanded reserves for animals and plants, necessitated by global destruction, in which robots play a passive and active role-or a proactive one, for example, by limiting a large spread of certain species by administering contraceptives, caring for plants or animals (in case of food shortages or injuries), or protecting plants and animals from poachers and vandals-one could cite a few more examples, although it must be emphasized that most of this lies far in the future. An advantage of these applications-apart from the economic potential-is that the animals are not disturbed by humans, do not take on their scent and thus are not rejected by their parents or other conspecifics, and are not habituated to human beings-and thus can continue to live in a natural way. If such a scenario were practicable, it would represent a paradigm shift. Automatic and autonomous systems and machines would not only be there to do specific jobs and to repair the damage they themselves have caused or to prevent their damage, but they would be useful helpers for all living beings.

\section{DISCIPLINES AND CLASSIFICATIONS WITH RESPECT TO ANIMALS AND MACHINES}

\section{Fields of Activity and Disciplines With Respect to Animals and Machines}

In the present context, various disciplines are involved, including above all, machine ethics, animal-computer interaction, and animal-machine interaction. Animal ethics and animal welfare are also relevant. In addition, the review lists robotics and artificial intelligence, which are important in the design and construction of systems and machines. Social robotics is also explained, a discipline that increasingly involves animals.

- Animal-machine interaction is the interaction (and communication) between animals and machines via an interface (Bendel, 2015). This is a relatively recent research field that is concerned with the design, evaluation, and implementation of machines such as drones, robots, and self-driving cars that interact with animals. It can build on the results of more specialized animal-computer interaction. 
- Animal-computer interaction-a research area pioneered by Mancini (2021)_-"aims to understand the interaction between animals and computing technology within the contexts in which the animals habitually live, are active and socialize with members of the same or other species, including humans" (Mancini, 2011). Computers, in turn, can be integrated into machines, so that the transitions to animal-machine interaction are fluid.

- The subject of machine ethics is the morality of machines, especially autonomous and semi-autonomous systems (Anderson and Anderson, 2011; Bendel, 2014b). The discipline can be classified under information and technology ethics or considered as equivalent to human ethics, focusing not on natural but on artificial moral agents. Representatives usually use the term machine morality in systematic terms similarly to the term artificial intelligence (in this case, the subject matter is meant, not the discipline). Machine ethics can be directed at humans or at animals. It can also be related to animal ethics (Bendel, 2013), since machines can be equipped with moral rules that apply to animals.

- Animal ethics deals with the duties of humans toward animals as well as the rights and values of animals (Singer, 2009). Over time, there have been many controversial debates, such as which animals can have which rights. Animal ethics is also concerned with the relationship between animals and (semi-) autonomous intelligent systems, such as artificial agents and certain robots (Bendel, 2014c). This review is not only about animal ethics, but also about animal welfare, the well-being of (non-human) animals.

- Robotics or robot technology is concerned with the design, development, control, production, and operation of robots, e.g., industrial or service robots. The purpose is often to extend the ability of humans to act (Christaller et al., 2001). Anthropomorphic or humanoid robots also involve the production of limbs and skin, facial expressions and gestures, and natural language capabilities. The focus of robotics is on physical robots with hardware and software.

- Social robotics, as a subfield of robotics and a neighboring discipline of sociology, psychology, and philosophy, to name a few, is concerned with sensorimotor machines created to interact with humans or animals, some of which are humanoid or animaloid (animal-like) in design (Bendel, 2021a). Examples include care robots, therapy robots, and sex robots. Entertainment and toy robots are also sometimes classified as social robots.

- The term artificial intelligence (AI) refers to a separate scientific field of computer science that deals with human thinking, decision-making, and problem-solving behavior in order to reproduce and replicate it using computer-based methods (Bendel, 2019b). In addition, animal thinking can be considered as a model or a completely different concept of intelligence (which does not correlate directly with either human or animal thinking) can be pursued. Machine learning and deep learning are playing an increasingly important role.

These disciplines have different backgrounds and degrees of maturity. It will be important to integrate them more to present an interdisciplinary or even transdisciplinary approach. Artificial intelligence and social robotics only have limited experience of interacting with and considering animals.

\section{Affected Animals and Typical Situations}

In this review, the focus is on different animals in different situations where machines are present. Machines and animals can be found in the home, in the garden, in parks, in urban locations, in agriculture, in the countryside (including the wilderness), and so on. Several types of animals are mentioned below, and the types of machines they may encounter are presented very briefly to keep typical situations in mind.

Pets come into contact with robotic vacuum cleaners indoors and robotic lawn mowers outdoors. They may have a close relationship with robotic toys or entertainment robots, e.g., robotic dogs like AIBO, as well as social robots that act as companions as if they were family members or friends. Increasingly, service robots (e.g., information, transportation, therapy, and care robots) are found in institutions, houses, and apartments (Bendel, 2017a), affecting the animals that live there according to plan. For example, automated feeding stations are used for hamsters or house cats that are left alone for a few days.

Various interactions are possible between technical systems and working and farm animals, e.g., between cows and milking machines or milking robots, and between farm animals such as cows and sheep and various components of housing, even if the latter are usually not technically very complex. Experiments are being conducted with virtual fences for farm animals, where the animals wear high-tech collars or devices on their heads that give them great freedom of movement but also prevent them from crossing a certain boundary by means of electric shocks (Fossgreen, 2017).

Wildlife (as well as livestock or working animals) can collide with harvesting and picking robots or other agricultural robots as they move through plantations, fields, and meadows. Scarecrow robots, such as those shaped like wolves, can also affect their activities. Many animal robots are being developed to perform functions in herds and flocks or "tasks" of animals as social beings or interacting organisms. The robots study groups of animals, influence them, try to direct and guide them, and make them behave in a certain way. Insights from swarm robotics-a research area dedicated to the coordination of multiple robots in a system—are essential here (Brambilla et al., 2013).

Robots that observe and control wildlife (working and farm animals, as appropriate), care for and feed them as needed, or euthanize and kill them in some extreme emergencies, are a vision of the future (Bendel, 2021a). Robots such as remotecontrolled drones and animal-like robots have been used for years to observe, photograph, and film flora and fauna. Now, semiautonomous and autonomous robots that can focus on specific plants and animals may be entering the scene.

\section{Passive, Active, and Proactive Machines}

The author distinguishes between passive, active, and proactive systems and machines (for the sake of simplicity, he sometimes speaks only of machines). This is not intended to create an irrefutable classification, but merely a helpful and fruitful 
one. What the author is addressing with these adjectives are the characteristics of machines and the relationship of those machines to animals. Passive machines, in principle, do not need a high degree of automation or autonomy, but may still exhibit one. Active machines require a certain degree of automation or autonomy, precisely so they can be active in a certain sense, namely to independently perform a certain task. Proactive machines depend on a high degree of automation or autonomy. The degree of automation or autonomy, together with the design of appearance, behavior, and sensory and motor capabilities determines the relationship to animals, whereby these can react differently. Examples of the types are given below.

- When the machine is passive, it observes, for example, domestic or big cats, it follows their trail and analyses their excretions, their movements, and their behavior. Normally it does not come too close to them, and when it does, it does so in a restrained and harmless manner. The passive machine tries not to interfere in animals' lives, either in a positive or negative way. In some cases, it remains completely invisible and barely perceptible; in others, it inserts itself into the social community as a creature-like element, without ultimately being able to make any significant contribution to it.

- When the machine is active, it spares, for example, a hedgehog or a swallow, sometimes instead of another animal to which it is not specialized. Often the machine itself presents a danger to the animal: it gets too close to it and threatens to collide with it. By modifying the normal machine, for example with approaches of machine ethics or animal-machine interaction in mind, one creates a special machine (called a moral machine in machine ethics), which in turn enables the protection of the animal, i.e., it has an at least partially positive effect (in the sense that a machine of this type can still pose a threat, simply by its presence, movement, and activity, but that it has been modified to avoid harming the animal as much as possible). However, an active machine could also protect a herd from wolves, for example. In this case, it is not a threat to one species, but a threat to another-however, the goal is not to kill these individuals, but to scare them away.

- A proactive machine does everything it can to help animals and to produce positive effects for them. While it has components of a passive or active machine, it goes far beyond their capabilities. Its most ambitious forms will only be feasible in the future, for example, systems which could not only detect fawns in a field and report them to the responsible parties, but also move the animals themselves to safety. This requires extensive sensory and motor skills. They could also be used to monitor, feed, and care for wildlife in vast nature reserves. In this way, wildlife is not habituated to or stressed by humans and can live their natural lives. Again, extensive sensory and motor equipment is required. In addition, a self-sufficient energy supply would be useful.

Of course, this is a wide-ranging classification, and one may wonder whether it covers everything and whether it is selective enough. However, it helps in further presentation and discussion, allowing the classification of existing prototypes and products.
TABLE 1 | Overview of the types with the examples covered.

\begin{tabular}{|c|c|c|}
\hline Passive machines & Active machines & Proactive machines \\
\hline Flying wildlife rescuer & $\begin{array}{l}\text { Automatic feeding } \\
\text { machines }\end{array}$ & $\begin{array}{l}\text { (Partially) Autonomous } \\
\text { system for households }\end{array}$ \\
\hline $\begin{array}{l}\text { Animal observation } \\
\text { cameras }\end{array}$ & LADYBIRD & $\begin{array}{l}\text { Autonomous system } \\
\text { for deer protection }\end{array}$ \\
\hline \multirow[t]{7}{*}{ Robot spies } & HAPPY HEDGEHOG & $\begin{array}{l}\text { Rescuers in natural and } \\
\text { environmental disasters }\end{array}$ \\
\hline & Angsa robot & $\begin{array}{l}\text { (Partially) Autonomous } \\
\text { system for reserves }\end{array}$ \\
\hline & $\begin{array}{l}\text { Wildlife vehicle collision } \\
\text { avoidance system }\end{array}$ & \\
\hline & Robocar & \\
\hline & DTBird & \\
\hline & Super monster wolf & \\
\hline & Robotic shepherd & \\
\hline
\end{tabular}

Moreover, it can be used to explain what capabilities machines and robots might have in the future.

\section{PASSIVE, ACTIVE, AND PROACTIVE SYSTEMS AND MACHINES}

In this section, examples are given for all three types-passive, active, and proactive systems and machines. This cannot be an exhaustive list-rather, the prototypes and products listed are widely known or familiar to the author, and they were also selected with the assumed readership in mind, in order to provide it with a broad overview and a structured presentation. Of course, there will be many more, and many an obvious idea (such as saving fawns) that is being implemented by several research institutions and companies.

Table 1 provides an overview of the examples discussed, arranged according to the aforementioned systematization. It is no coincidence that the most examples are found within active systems and machines. This area is benefiting from the current boom in robotics and artificial intelligence. However, it will also become apparent that a particularly large number of prototypes can be found here.

\section{Passive Systems and Machines Fliegender Wildretter by DLR}

Projects to protect animals in agriculture exist in large numbers. The main aim is to detect wild animals such as fawns in grain and corn fields in good time before a combine harvester could collide into them. Usually, a drone flies in front of the combine and tries to spot the potential victim. If it succeeds, a message is transmitted to a human, who takes further steps.

The Fliegende Wildretter (Flying Wildlife Rescuer) (from 1999 on) of the Deutsches Zentrum für Luft- und Raumfahrt e.V. (DLR) (German Aerospace Center), which can almost be called a 'classic', follows exactly this principle (Wimmer et al., 2013). A drone automatically flies over the field before or during harvest. It stores high-resolution thermal images 
and their location data every second. Rehkitzrettung Schweiz (https://www.rehkitzrettung.ch) also works with a drone. In both projects, the driver of the combine harvester must stop and the driver or a helper must remove the fawn from the field manually.

The Flying Wildlife Rescuer is a project in the context of animal welfare and animal-computer interaction as well as animal-machine interaction. It must be added that economic reasons also play a role. For example, the combine should not fail in operational terms and should not need to be cleaned. Every accident with a larger animal can mean a loss of earnings for the farmer. There is a chance that the system will become a standard solution for all cases of this kind.

\section{Animal Observation Cameras}

Cameras for animal observation are widely used. They are installed in forests, on individual trees, bushes, and rocks in the steppe and savannah or in other places. The main purpose is to monitor wild animals. Microphones are also used sporadically to record animal sounds.

According to its own information, KORA in Switzerland researches the way of life of predators and monitors the development of their populations (https://www.kora.ch). They also observe the impact of predators in modern cultural landscapes and work out the basics for a low-conflict coexistence of large predators like bears and wolves with humans. Cameras are used for animal observation. The memory cards are exchanged on a regular basis. There is automatic remote image transmission via SIM card only in some cases, which makes the project costly. Many recordings cannot be used for data protection reasons because strollers can be seen on them (Yürekkirmaz, 2022).

The animal observation cameras are mainly an animal observation project. The observation can be done without interference and disturbance from humans (if one ignores the installation of the cameras and the replacing of the memory cards). The system is a standard solution for all cases of this kind. However, there is some room for improvement, for example with regard to the automatic transfer of images.

\section{Robot Spies}

Monitoring systems and robotic spies are used for animal observation, mostly in the wild. They are either abstractly designed or modeled on the nature of the animals to inconspicuously blend into the community or even attract animals to better observe and analyze them, but without disturbing them. They are either enhanced cameras or multimedia systems that can move and protect themselves or complex robots that adapt to their environment.

Filmmaker John Downer has created artificial monkeys, wolves, hippos, turtles, alligators, etc., to observe appropriate wildlife and obtain spectacular images (http://jdp.co.uk). His robots are very intricately designed and resemble the animals they mimic in almost every detail. They can often move their limbs and move forward on four legs. Behind their lifelike eyes are cameras for observation. Most robotic spies will be remotecontrolled robots, but there is nothing to stop autonomous robots from being used as well. The important thing here is that the artificial animal always aligns itself with the animal of interest to fulfill its purpose. Regarding the BBC series "Spy in the Wild," the mentioned website states:

In one of the most innovative natural history series ever presented, Spy in the Wild deploys over 30 ultra-realistic animatronic Spy Creatures to go undercover in the animal world. [...] These robotic look-alikes make all the right moves to not only be accepted by animals but also interact with them, providing revelatory insights into their world.

If one watches the films, one gets to see how the animals are disinterested or how they curiously approach the robots, touch them, nudge them, try to ensnare them, and-in the case of a turtle-try to mate with them. Thus, the artificial creatures are sometimes obvious foreign bodies, sometimes supposed conspecifics, which raises the question of deception and cunning, which is otherwise dealt with mainly in relation to humans (see the remarks of Bendel and Kreis in Schulze et al., 2021)-and what already marks the transition to active machines.

The robot spies are mainly an animal observation project. The observation can be done without interference and disturbance from humans (if one ignores the transport of the robots). In addition, animal-machine interaction, animal-computer interaction, and social robotics are required as disciplines. There is a chance that the robots will become a standard solution for all cases of this kind. However, it is costly to create them and there are few uses for them.

\section{Overview of Passive Machines}

Table 2 provides an overview of the passive systems and machines covered. Indications of the machine type, development status, type of problem solution, and influence on animal welfare are also given.

\section{Active Systems and Machines \\ Automatic Feeding Machines}

Most commonly, cats and dogs live in households-besides hamsters, guinea pigs, and fish, which are restricted in their freedom of movement. While dogs are quite dependent on humans, this is less the case with cats, provided they can leave the house and are used to taking care of themselves. Dogs, in principle, can also supply themselves, but rarely do so as domestic dogs-they must first become wild dogs that roam around looking for scraps or chasing small animals. Automatic feeders provide a basic food supply. There are simple versions for pets-feeding robots, on the other hand, are found mainly in stables.

Sure Petcare's microchip feeder (https://www.surepetcare. com) is designed for multi-pet households where food theft by other animals is a problem. It ensures that specific food is eaten by the correct animal and is suitable for wet and dry food. An automatic closing lid ensures that food stays fresh longer. The Feeder robot is a WiFi-enabled automatic pet feeder, according to https://www.litter-robot.com/feeder-robot. html. The website says: "You can operate this automatic pet food dispenser through unit control or the AutoPets Connect app, 
TABLE 2 | Overview of passive machines.

\begin{tabular}{|c|c|c|c|c|}
\hline Passive machines & Machine type & Development status & Problem solution & Animal welfare \\
\hline Flying wildlife rescuer & Monitoring drone & Prototype & $\begin{array}{l}\text { Prevents the chopping of } \\
\text { fawns in the field }\end{array}$ & $\begin{array}{l}\text { Protects fawns in fields } \\
\text { May disturb other animals like birds }\end{array}$ \\
\hline $\begin{array}{l}\text { Animal observation } \\
\text { cameras }\end{array}$ & Monitoring cameras & Product (standard solution) & $\begin{array}{l}\text { Helps to observe and count } \\
\text { wildlife }\end{array}$ & $\begin{array}{l}\text { May disturb wildlife when setting up and changing } \\
\text { memory card }\end{array}$ \\
\hline Robot spies & Robot with cameras & Product (individual solution) & $\begin{array}{l}\text { Helps to observe and film } \\
\text { wildlife }\end{array}$ & $\begin{array}{l}\text { May disturb wildlife when setting up and changing } \\
\text { memory card }\end{array}$ \\
\hline
\end{tabular}

which offers customizable programming options for your pet's mealtime needs from the convenience of your phone-even when you're not home!"

Automatic feeding machines are an animal welfare and animal-computer interaction or animal-machine interaction project or product. Some cats and dogs will not be satisfied with being fed by a vending machine. It is important to them that the owner feeds them and has social interactions with them before or after the process. However, in the temporary absence of humans, this solution is better than no food at all. The system is a standard solution for all cases of this kind.

\section{LADYBIRD}

Indoor household robots encounter pets as well as small wild animals, especially insects. In some cases-with specialized robots-the pets are to be entertained and kept moving (Bendel, 2021a), in other cases-this concerns various service robotsthey are simply disturbed and distressed by the robot. Beetles, spiders, caterpillars, etc. are in particular danger-the machines are capable of injuring and killing them. This can be prevented by programming certain rules into them, given suitable sensors and actuators.

LADYBIRD is the prototype of an animal-friendly-more precisely, ladybug-friendly-vacuum cleaner robot (Bendel, 2017b, 2019a). Back in 2014, the design study, which provided rough information about the desired appearance and planned functions of the device, was created and published via the website https://www.maschinenethik.net. The idea was repeatedly mentioned at lectures, in publications and interviews. On the one hand, it met with goodwill among listeners and readers, on the other hand with media and scientific interest, because the sense and purpose of a simple moral machine became visible and the concern of machine ethics could be made understandable. Years later, a fundamental work on machine ethics would begin with this very example of a moral machine (Misselhorn, 2018). In 2015, an annotated decision tree for LADYBIRD was created.

In this modeling, the activity of hoovering is assumed (Bendel, 2017b). It is checked whether something is in the path of the vacuum cleaner robot. If this is the case and it is an animal, it is clarified what size it is. A cat is not problematic given the size of the suction tube or nozzle, but a ladybug is. In this case, the operation is immediately stopped. The moral assumptions are crude and simple. They do not have to be shared by everyone. They do not even have to be, because different devices can be offered, the customer can be made aware of the extensions and limitations via product information, labels, and certificates at the time of purchase, and they can be offered to modify the device if they have divergent needs. For example, some people get out the vacuum cleaner to suck up spiders or basement woodlice. They would be helped if LADYBIRD made an exception for these animals. Admittedly, this goes against the animal friendliness approach. If no living creature is affected, other possible circumstances are included in the modeling.

In 2017, LADYBIRD was prototyped as part of a practical project at the School of Business FHNW (Bendel, 2019a). The three-person team, supervised by the author, used the annotated decision tree described above. It built a color sensor into the machine as a recognition system. Other desired and useful components-such as motion sensors or systems with size measurement or image and pattern recognition-were not considered because the business computer scientists had too little experience in these areas and too little time. The result was a primitive robot that could at least illustrate the concern and the implementation possibilities. It recognizes an abstracted ladybug, stops in front of it, and emits a beep-realized by the team as a woman's cry for reasons unknown. LADYBIRD was presented at the AAAI 2017 Spring Symposium "AI for Social Good (AISOC)" (Bendel, 2017b).

LADYBIRD is a project within the framework of machine ethics (together with animal ethics). The main purpose was to show how machine ethics can be used in a simple but effective way and how a simple moral machine can be implemented. In addition, animal welfare is important in the project, although one may question whether it is a pressing issue. It has been suggested that such a solution may also turn against animal welfare, for example if (despite being beneficial predators) spiders are considered collateral damage or are deliberately sucked in. There is a chance that the animal-friendly component will become a standard solution for all cases of this kind.

\section{HAPPY HEDGEHOG}

Household robots for outdoor use, such as robotic lawnmowers, encounter domestic, and farm animals, but especially small and large wild animals, such as hedgehogs, martens, snakes, and birds of all kinds. These are at risk-the machines can injure and kill them. This, in turn, can be prevented by programming certain rules and using certain sensors and machine learning capabilities. Other service robots such as pool robots are hardly a danger to animals.

HAPPY HEDGEHOG (HHH) is the prototype of a petfriendly_or more precisely hedgehog-friendly-robotic lawn 
mower (Bendel et al., 2021). Thus, the author revisited the idea of LADYBIRD in 2019. With the ladybug-friendly robot, meanwhile, the main point was to illustrate the principle-to show that moral rules can be implanted in (simple) machines and thus turn them into (simple) moral machines. In reality, ladybugs on the floors of apartments and houses are not a pressing problem. Yet, of course, some insects could be saved in this way. Hedgehogs killed by robotic lawnmowers are indeed tragedies. Probably thousands die in this way every year worldwide, mostly young specimens that are surprised by the machine and cannot or will not go on. These may be few compared to the victims of the same species in road traffic, but it is a suffering that can be avoided without much effort. An annotated decision tree did not exist in this case. But the four-person team that took on the challenge this summer as part of a hands-on project based on the LADYBIRD project.

$\mathrm{HHH}$ is technically more advanced than its predecessor (Bendel et al., 2021). Like LADYBIRD, it drives around autonomously. It is equipped with a thermal imaging camera. This allows it to spot living creatures and warm objects in its path. When it encounters them, it pauses and applies its second method while pointing its relatively high-positioned camera at the unknown object. Using machine learning-the team had fed it with more than 300 hedgehog images-it was able to detect hedgehogs in the lab setting with ease. When it does, it stops working for an extended period. At this point, it would be useful for it to send a message to the owner. A signal tone as with LADYBIRD is only recommended to a limited extent, since when operating a lawn mowing robot-especially on larger areas such as golf courses-there is not always someone around. In principle, HAPPY HEDGEHOG can also be trained with other animal images, such as foxes, birds, and insects.

$\mathrm{HHH}$ is a project within machine ethics (in cooperation with animal ethics). The project LADYBIRD should be continued and the predecessor robot be improved. Moreover, it is about animal welfare and, in this case, about a real, urgent problem whose solution was strikingly simple, even though the use of such a robotic lawnmower may prove to be a complex challenge in practice (e.g., hedgehogs turned the other way, tall, dense grass, or dirty lenses). There is a chance that the animal-friendly component will become a standard solution for all cases of this kind.

\section{Angsa Robot}

Household robots for outdoor use also include cleaning robots for lawns, a small but interesting market when you think of swimming pools, soccer fields, or golf courses. They encounter domestic and farm animals, but especially small and large wild animals. Very small animals such as slow worms, frogs, snails, and insects are at high risk-the machines can injure and kill them. This, too, can be prevented by installing appropriate sensors, actuators, and AI systems.

A cleaning robot for lawns is being developed by the German company Angsa (https://angsa-robotics.com). According to the manufacturer, the artificial neural network built into the robot enables reliable detection of small and partially hidden objects. It is trained, according to the website, using its own data set of real garbage images. For example, the prototype can distinguish cigarette butts and French fries from other objects such as leaves, dirt, or insects. Targeted removal guarantees protection against damage to surfaces or insects.

Angsa robot is a project in the context of animal welfare. Certainly, insect-friendliness serves the company's marketingbut it is a real, pressing problem, especially since, for example, the mass death of bees leads to a loss of plant biodiversity. Machine ethics was not explicitly involved or mentioned as a discipline here, but one can also situate the project in this context. There is a chance that the animal-friendly component will become a standard solution for all cases of this kind.

\section{Wildlife Vehicle Collision Avoidance System}

Many accidents occur on the roads, not only due to the collision of conventional or automated vehicles, but also due to the collision of conventional and automated vehicles and animals. Cars and trucks are an especial danger when driving at high speed on rural roads and highway. Some modern cars, such as the Tesla Model S or Mercedes S-Class, brake for large animals to prevent damage to the vehicle and injury to the occupants. Another option is to warn the driver. This can be done via the vehicle itself (e.g., using sounds or light signals) or via an external system.

The Wildlife Vehicle Collision Avoidance System is a prototype from a research facility in India (Kurain et al., 2018). The goal of the external system is to use light signals to alert drivers to wildlife at an early stage. Delineators on the side of the road use infrared sensors to detect animal movement within a range of 5-12 m. The images in the researchers' paper show that deer are most commonly in view. The system then warns drivers by illuminating LED lights. The system is useful where animals regularly cross the road. It will be especially effective at night when animals are barely visible and at the same time the signals are clearly visible from a distance.

The Wildlife Vehicle Collision Avoidance System is a project in the field of animal welfare, animal-computer interaction, and animal-machine interaction. In addition, economic and operational considerations will also play a role here-an accident with a larger animal damages the vehicle to the point of total loss and potentially paralyzes traffic, possibly resulting in the deployment of police and ambulances-as well as potentially seriously harming the driver. It is unclear whether the solution will prevail. It is very costly to install such systems in all places where there is wildlife crossing.

\section{Robocar}

On the road, many accidents occur not only due to the collision of vehicles, but also due to the collision of vehicles and animals. Some modern cars brake for large animals to prevent damage to the vehicle and injury to the driver. Small animals, on the other hand, are simply run over, but this could be avoided by certain rules and novel technologies-built directly into the vehicles (Bendel, 2014a), although legal regulations-such as the ban on braking for small animals-would have to be adapted at most. That some of them, like hedgehogs or toads, are worthy of protection is already proven by the warning signs at the roadside, which, however, are unlikely to have any effect. 
Robocar is a design study from 2014 that was linked to the 2016 modeling (Bendel, 2016a). The idea is that the robotic car or a car with Advanced Driver Assistance Systems (ADAS) can break for or avoid small animals. An annotated decision tree with moral assumptions and justifications leads to a different option depending on the situation. Nowadays, safely driving over between tires, possibly combined with a slight evasive maneuver, is an option even for medium-sized animals. For example, an SClass Mercedes can raise itself $8 \mathrm{~cm}$ in the event of an impending accident to better protect occupants in the case of a side impactthis could also be made useful for animals.

Robocar is a project in the context of animal welfare and machine ethics (in collaboration with animal ethics). It is, as mentioned before, purely conceptual. It has been presented not only at scientific conferences, but also at car manufacturers such as Daimler and Audi. There, however, the author's impression is that the killing of small animals is considered collateral damageat least no activities were subsequently announced that would solve the problem. As indicated, the law may also prohibit braking for small animals, depending on the country. There is a chance that the animal-friendly component will become a standard solution for all cases of this kind. However, this only applies if people are protected at the same time. For example, the system should only become active when there is hardly any traffic on the roads.

\section{DTBird}

Wind turbines are widespread in countries such as Germany, Denmark, and Spain or in the USA-for example in Texas, Iowa, Oklahoma, Kansas, California, and Illinois. They can kill birds and bats through their moving rotors. It is especially dangerous when flocks get too close. But individual birds of prey such as hawks are also at high risk. The animals cannot properly judge the movements of the turbines and are caught by the rotors. In some areas, there are dozens or hundreds of towers with rotors, making it difficult for animals to fly through unharmed.

DTBird is used for bird monitoring and collision avoidance at wind turbines (May et al., 2012). Optical sensors are deployed to automatically detect birds. A display in a control center shows the user the size of the birds and, if detected, the species. The system can emit warning sounds and stop the rotors. While detection and analysis basically work well, even for more distant birds, stopping the rotors immediately is almost impossible, and it is simply up to the laws of physics whether the bird survives or not. However, it is possible to gain some time with additional measures, such as scaring by sounds or light signals. DTBat, as the name suggests, focuses on bats.

DTBird is a project in the context of animal welfare, animalcomputer interaction, and animal-machine interaction. There are also economic considerations, because in extreme cases, a bird strike can damage the equipment-think of large birds like storks or geese. In principle, falling birds can also injure other animals or even humans, and the carcasses can in turn attract other birds and potential bird prey, creating a vicious spiral. There is a chance that the system will become a standard solution for all cases of this kind. However, the overall system must respond more quickly to approaching birds and shut down faster.

\section{Super Monster Wolf}

Both fields and herds are threatened by animals, by pests or predators. In one case there is the loss of the harvest, in the other the loss of herd animals and thus the profit from wool, leather, milk, and meat. Accordingly, protective measures have been devised from time immemorial. For the first case, traditional scarecrows are often sufficient. However, robots can also be used as bird and animal scarecrows. These can also keep the animals away from other plants, such as those that might be dangerous to them.

The Super Monster Wolf was developed in 2017 by JA Kisarazushi (a Japanese agricultural association) and the University of Tokyo. It uses infrared sensors to detect animals approaching a rice field. The German magazine Golem wrote about it on August 28, 2017:

It drives away deer, birds, wild boar and even bears by making loud noises: at up to 95 decibels, it can howl, hiss, talk like a human, mimic gunfire-in total, the machine can handle 18 different sounds. The sounds are supposed to vary so that the animals to be driven away don't get used to them. (Pluta, 2017, own translation)

However, according to the author of the magazine, the wolf cannot run after other animals. It stands on solid metal legs and can only turn its head back and forth with its red eyes illuminated by LEDs. The power for sensors, LEDs, motors and sound generator-according to the author of the magazine-is supplied by a solar module. Obviously, the robot is not particularly nice to animals, so it is not an animal-friendly machine in the classical sense.

The Super Monster Wolf is a project in the context of animalmachine interaction. Animal welfare comes into play when the animals are kept away from dangerous plants. In addition, economic considerations can be made, for example, in terms of the plants that are not harmed and the profits that are maintained by protecting the crop. It is unclear whether the solution will prevail. It is very costly to install such systems in all places.

\section{Robotic Shepherd}

Both fields and herds are threatened by animals, by pests or predators, as already explained. With a view to protecting herd animals, shepherds work with herding dogs. However, one can also replace herders or herding dogs (or both) with robots. This is by no means trivial, since herders and herding dogs have a social and hierarchical relationship with each other and with the herd animals. The question is whether to model this or rely on novel configurations.

In May 2020, the media was interested in the video "Autonomous farm work-enter the robots" from RocosRobot Operations Platform (https://www.youtube.com/watch? $\mathrm{v}=\mathrm{RBLnAhzPpTQ}$ ), showing a Boston Dynamics robot trying to be a herding dog. The artificial quadruped could be seen running toward a flock of sheep. The Verge magazine said: "Now, it's clear that the video is mostly a fun teaser rather than a serious claim by Rocos (or Boston Dynamics) that robots will soon be replacing sheepdogs." (Vincent, 2020) According to the magazine, it raises 
TABLE 3 | Overview of active machines.

\begin{tabular}{|c|c|c|c|c|}
\hline Active machines & Machine type & Development status & Problem solution & Animal welfare \\
\hline $\begin{array}{l}\text { Automatic feeding } \\
\text { machines }\end{array}$ & Automat & Product (standard solution) & $\begin{array}{l}\text { Feeds pets and farm } \\
\text { animals in the absence of } \\
\text { the owner }\end{array}$ & $\begin{array}{l}\text { Provides pets } \\
\text { Human contact is missing } \\
\text { Animals must get used to automat }\end{array}$ \\
\hline LADYBIRD & Vacuum cleaner robot & Prototype & $\begin{array}{l}\text { Prevents the sucking in of } \\
\text { insects such as ladybugs }\end{array}$ & Protects insects like ladybugs \\
\hline HAPPY HEDGEHOG & Robotic lawn mower & Prototype & $\begin{array}{l}\text { Prevents chopping } \\
\text { hedgehogs }\end{array}$ & $\begin{array}{l}\text { Protects hedgehogs } \\
\text { Robot may hurt other small animals }\end{array}$ \\
\hline Angsa robot & Lawn cleaning robot & Prototype/Product & $\begin{array}{l}\text { Prevents harming insects } \\
\text { and other small animals }\end{array}$ & $\begin{array}{l}\text { Protects insects and other small animals } \\
\text { Robot may hurt other small animals }\end{array}$ \\
\hline $\begin{array}{l}\text { Wildlife vehicle collision } \\
\text { avoidance system }\end{array}$ & Warning system & Concept/Prototype & Warns of approaching deer & May disturb and irritate animals with light signals \\
\hline Robocar & Modeling & Concept & $\begin{array}{l}\text { Allows braking for small } \\
\text { animals }\end{array}$ & Protects small animals \\
\hline DTBird & $\begin{array}{l}\text { Warning and } \\
\text { intervention system }\end{array}$ & Product & $\begin{array}{l}\text { Warns of birds and stops } \\
\text { wind turbine }\end{array}$ & $\begin{array}{l}\text { Protects birds } \\
\text { System may hurt other animals }\end{array}$ \\
\hline Super monster wolf & Scare robot & Prototype & $\begin{array}{l}\text { Scares away wild animals } \\
\text { from the field }\end{array}$ & Protects fields with its plants and animals \\
\hline Robotic shepherd & Shepherd robot & Prototype & Helps herding herds & Protects sheep or goats \\
\hline
\end{tabular}

an intriguing question: If this were the case, "how well would the robots fare" (Vincent, 2020)? "Terrible" is the clear answer from sheep farmer and author James Rebanks. "The robot might be an amazing tool for lots of things but it is worthless and unwanted as a sheepdog..." (Vincent, 2020).

The robotic shepherd is a project within the framework of animal-machine interaction. One must add, however, that it was probably-as the review also suggests-a fun or marketing video. In serious projects, animal welfare is at play, as herd animals are protected from wild animals. In addition, economic considerations can be made, for example, in terms of animals that are not harmed and can be put to use (such as obtaining wool). It is unclear whether the solution will prevail. It is very costly to install such systems in all places and of unclear benefit for the animals concerned.

\section{Overview of Active Machines}

Table 3 provides an overview of the active systems and machines covered. Again, information of the machine type, development status, type of problem solution, and influence on animal welfare is given.

\section{Proactive Systems and Machines (Partially) Autonomous System for Households (Vision)}

In many households there are cats and dogs. While dogs are quite dependent on humans, this is less the case with cats, provided they can leave the house and are used to taking care of themselves. Dogs can in principle also take care of themselves, but they rarely do so as domestic dogs-they must first become wild dogs, which admittedly only happens when the owner abandons and leaves them or they are born and grow up without human care. The described feeders provide a basic supply, but cannot offer petting, entertainment, or training. A problem that may become more prevalent in the future is that pet owners are not consistently able to care for their pet, whether they are ill, absent, or cut off from their home due to environmental disasters.

One ambition in this area is a fully automated, multicomponent system for mammals, amphibians, and reptiles in the home. An automatic feeder could provide food and water to the animals. An autonomous robot could pet the animals, brush and wash their fur, and play with them. It could speak in the owner's voice and use a human voice to prompt the animals to perform certain actions, such as sitting down-as shown by studies at Yale University (Qin et al., 2020). Remote access would allow the owner to show himself on the display and speak directly to the animal. While an automat could be constantly plugged in, a robot-like some social robots and service robots do-could return to its charging station on its own.

The (partially) autonomous system for households would be a project in the context of animal welfare and animal-computer interaction, as well as animal-machine interaction. One must also make critical considerations here: Not all pets would be able to cope with the absence of humans in the long run-but for a few days, such systems could be a solution. The animals need to get habituated to the robot during the preparation period, so that they can get accustomed to the robot and have positive experiences by interacting with it. In some cases, the animals could live lives that are as species appropriate as possible, and they could gain pleasure and enjoyment from natural behaviors. Social robotics is gaining momentum in this area. This is because it is about the machine getting very close to the animal and making it feel comfortable. It is unclear whether the solution will prevail. It is very costly to install such systems in all places and of unclear benefit for the animals concerned.

\section{Autonomous System for Deer Protection (Vision)}

The systems described for detecting deer in fields and rescuing them are in the majority not fully automatic or autonomous. They depend on an attentive driver who receives and implements 
the warning, or at least on a helper who retrieves the fawn from the field. Ultimately, these are very costly projects that must first cover their costs. In the future, combines may need to drive autonomously for various reasons and suitable personnel may not always be available. The Coronavirus pandemic has shown that shortages of skilled workers quickly arise in certain areas.

A proactive solution in this context would be fully automated animal rescue systems. For example, fully automated fawn rescue systems could be developed as a continuation of the aforementioned work. A drone spots the animal in the field and reports this to the combine-then a robot picks up the fawn and brings it to safety (in existing projects, a human helper does this). One advantage of this would be that the animal would not take on the scent of a human and could immediately return to the care of its mother. Such a solution also makes economic sense, provided that the costs of procuring and operating the robot are kept within reasonable limits. At the moment, it is technically hardly feasible, mainly because of insufficient mechanical capabilities of current products.

The autonomous system for deer protection would again be a project in the context of animal welfare and animal-computer interaction as well as animal-machine interaction. Again, it must be added and emphasized that economic reasons also play a role. For example, the combine should not break down and should not need to be cleaned. At the same time, the previous costintensive process requiring manual labor should be automated, which can save money under certain conditions. It is unclear whether the solution will prevail. It is of unclear benefit for the animals concerned.

\section{Rescuers in Natural and Environmental Disasters (Vision)}

In the future, crises and disasters could increase further. These include floods, wind damage, and fires, which have been increasingly experienced around the world since the turn of the millennium, and some of which were man-made. In the Coronavirus pandemic, service robots and social robots helped patients by bringing them food and medicine, and relieved caregivers by measuring patients' fevers and disinfecting objects in rooms (Bendel, 2020).

In many crises and disasters, especially natural disasters, animals become trapped in homes and on remaining patches of earth and in recently formed crevices and pits, and they become acutely threatened by disease, flash floods, and fire. Humans will expend all the power they have on their own kind, using both their physical strength and the capabilities of machines and robots. Partially autonomous and autonomous robots would be an option for injured and threatened animals. They could carry them to safety, care for them, and doctor them. In doing so, unlike with humans, the goal would not necessarily be to help every individual or even to perform justifiable triage. Rather, similar to what Bendel (2016a) has argued for in regards autonomous driving, the sum of the saved must be appropriate. Improvements and implants in the sense of animal enhancement could also help living beings cope with changing environmental conditions (Bendel, 2021b).
The rescuers in natural and environmental disasters would also be a project in the context of animal welfare and animalcomputer interaction as well as animal-machine interaction. It must be repeated that economic reasons also play a role, and this in a context where enormous costs are caused by the destruction and the removal of the destruction. In addition, the aim is to relieve rescue workers who have a priority to take care of humans. From that point of view, not only the animal is in focus here, but also the human being. There is a chance that the system will become a standard solution for all cases of this kind. However, technical development must continue to progress for this to happen.

\section{(Partially) Autonomous System for Reserves (Vision)}

Nature reserves are an opportunity for animals and plants. However, they are usually just small areas that are permeable to people and even vehicles. To some extent, this is necessary because even nature reserves need to be supervised and maintained when the ecological balance is disturbed. One idea, given the prevailing trend of expanding urban areas and settlements and declining biodiversity, would be to greatly expand the areas and make them more difficult or impossible to access for humans-at least for those whose presence is not necessary for conservation (Bendel, 2021a). Human contact is in many cases harmful to animals and plants. This applies not only to poachers, but also to tourists and locals.

The principle of the nature reserve is thus reversed, so to speak, and one could almost say that from now on humans live in reserves so that the environment is protected from them. In this version, semi-autonomous and autonomous robots would play a passive and active role, for example by observing animals and providing them with food and water-and in some cases also a proactive one, by limiting a large spread of certain species, e.g., by administering contraceptives, taking care of plants or animals (in case of food shortage or injuries), or ensuring the protection of plants and animals from the grasp of poachers and vandals, as it were as a shield or assistant to the animals. An advantage of these applications-apart from the economic potential-is that the animals do not take on the scent of humans, are not rejected by parents or conspecifics, and are not habituated to humansand can therefore continue to live naturally. Care must be taken when using remotely controlled or autonomous flying machines and robots, namely drones-they cause stress in some animals (Ditmer et al., 2015). In addition, they have difficulty flying into forests.

The (partially) autonomous system for reserves could benefit from machine ethics. Some of the machines will have to make moral decisions, such as when an animal is injured and the question arises of whether to kill it. But such decisions can also be made by humans if the volume of cases is not too large, such as from a control center. Otherwise, it is still about animal-computer interaction, animal-machine interaction, and animal welfare. There is a chance that the system will become a standard solution for all cases of this kind. However, technical development must continue to progress for this to happen. In addition, appropriate political and legal conditions must be created. 
TABLE 4 | Overview of active machines.

\begin{tabular}{|c|c|c|c|c|}
\hline Proactive machines & Machine type & Development status & Problem solution & Animal welfare \\
\hline $\begin{array}{l}\text { (Partially) Autonomous } \\
\text { system for households }\end{array}$ & Automat/Support robot & Vision & $\begin{array}{l}\text { Feeds and takes care of } \\
\text { pets in the absence of the } \\
\text { owner }\end{array}$ & $\begin{array}{l}\text { Provides pets } \\
\text { Human contact is missing } \\
\text { Animals must get used to automat/robot }\end{array}$ \\
\hline $\begin{array}{l}\text { Autonomous system } \\
\text { for deer protection }\end{array}$ & $\begin{array}{l}\text { Support } \\
\text { robot/Monitoring drone }\end{array}$ & Vision & $\begin{array}{l}\text { Prevents the chopping of } \\
\text { fawns in the field }\end{array}$ & $\begin{array}{l}\text { Protects fawns in fields } \\
\text { Robot could scare animals } \\
\text { Robot may hurt other animals }\end{array}$ \\
\hline $\begin{array}{l}\text { (Partially) Autonomous } \\
\text { system for reserves }\end{array}$ & Support robot & Vision & $\begin{array}{l}\text { Provides and cares for } \\
\text { wildlife in reserves }\end{array}$ & $\begin{array}{l}\text { Provides wildlife } \\
\text { Robot could scare animals } \\
\text { Robot may hurt other animals }\end{array}$ \\
\hline
\end{tabular}

\section{Overview of Proactive Machines}

Table 4 provides an overview of the proactive systems and machines covered. Again, indications of the machine type, development status, type of problem solution, and influence on animal welfare are given.

\section{DISCUSSION}

In this section, the author discusses the proposed types and presented examples of robots, with respect to the protection and preservation of animals and animal species. Challenges and opportunities that have been shown in the presentations are addressed, always referencing the classification of passive, active, and proactive robots.

\section{Passive, Active, and Proactive Machines}

Sufficient examples could be located in all three categoriespassive, active, and proactive machines. Despite this, most robots or machines that enter into a certain relationship with animals, partly in the form of prototypes and partly in the form of products, fall into the passive or active categories. They serve to observe, entertain, feed, and care for non-human creatures, and they can help to avoid animal suffering. This is the unique selling point, so to speak, of active robots that direct their focus to a specific animal or problem. Proactive machines can be easily conceived but are difficult to implement. They also require economic foundations, political decisions, and legal frameworks that still need to be addressed. They will usually also have passive and active components; just as active machines often have passive components. So, the three categories are related in certain ways. The more complex manifestations build on the less complex ones. This allows earlier stages of development to be exploited, saving development time and cost. It has already been indicated that the classification is not necessarily selective. However, it helps in sorting and classifying robots in this area and stimulates considerations about the category of proactive robots, which is hardly covered by reality.

\section{Automatic, Partially Autonomous, and Autonomous Machines}

Passive machines are mostly less complex machines that function automatically or are directly controlled or remotely controlled, or semi-autonomous systems that require regular control by a human being in addition to their autonomous functions. Active machines are often semi-autonomous or autonomous machines, especially robots. Even with given autonomy, they are typically taken to a specific area of operation, repeatedly retrieved, maintained, and recharged, and humans intervene when certain messages and warnings are issued by them. Proactive machines would typically be semi-autonomous and autonomous systems, with a quantitative and qualitative shift: they would have to be autonomous for extended periods of time, for example, with respect to energy supply. They would also have to be highly flexible and reliable-think of the example of nature reservesat least in their special field, or as generalists they would have to be able to perform a wide range of tasks, which is admittedly technically unfeasible right now. Here and there, humans will also have to intervene, although this should partly be done remotely, and there is hope that one day machines will be able to repair each other and-for example in the event of a malfunction or total loss-transport them away.

\section{Service Robots and Social Robots}

Among the passive and active machines, classical support systems and service robots mainly came up. However, social robots were also present, if one uses this term broadly and includes observation robots for filming, which are even sometimes accepted into the social community of animals, or certain animal-friendly machines such as LADYBIRD and HAPPY HEDGEHOG, which assume a great closeness to the animal and then contribute to animal welfare and animal protection on the basis of moral rules and appropriate sensors and motor functions (Bendel, 2021a). Proactive machines could particularly benefit from social functions and capabilities and in this sense to some extent complement and replace both animals and humans. For example, if only a few individuals of a herd remained in nature reserves due to unfortunate circumstances, social robots could fill this gap, even in the appropriate function or at the appropriate hierarchical level, depending on programming and design. They could play a special role in raising young when parents have been killed - that (appropriately prepared) things are accepted as parental substitutes has been proven by some studies since Harry Harlow's experiments (Harlow, 1959). Overall, there is a trend for service robots to take on more and more social functions, 
including getting help from humans (think riding an elevator or climbing stairs). The animal world could also benefit from this and thus experience both practical help and emotional affection.

\section{Tasks of Disciplines and Interdisciplinarity}

Several disciplines that can play a role in this context were presented. For passive machines, insights from animal-computer interaction, animal-machine interaction, and robotics, among others, come into play. For active machines, other disciplines such as machine ethics and, as indicated earlier, social robotics help shape appearance, behavior, and interaction. Proactive machines will require all these disciplines to a great extent. This also means new requirements for interdisciplinarity: robotics must consider fields that it does not always give top priority to, or even accept their temporary or permanent leading role. However, social robotics and machine ethics must also be modestly applied because the prototypes they have produced so far are not exactly characterized by outstanding motor skills. The already aged NAO is still the most agile, but it falls far short of high-end service robotics devices such as Boston Dynamics' Atlas and Spot (though it is also only a fraction of the cost). However, highly developed motor skills will be in demand in rough terrain and the great outdoors. Social robots like Pepper, Cruzr, and Paul, despite their voice and face recognition capabilities, would be little more than a bit of junk in a nature preserve, unable to get off the ground. In addition, of course, they would have to be prepared for entirely new requirements within the limits of their capabilities, would have to recognize animal voices, and would have to recognize animal faces. In fact, initial efforts exist in both areas: some projects are trying to understand animal languages using machine learning and inventing translation systems (e.g., the Earth Species Project, https://www.earthspecies.org); others are developing algorithms and systems for facial recognition in non-human primates, big cats, bears, and wolves (Deb et al., 2018). So, artificial intelligence would have to play a major role in some systems, especially when it comes to nature reserves populated and overseen by robots, and it is classical robotics that needs to take its younger siblings like social robotics by the hand.

\section{Machines as Parts of Systems}

In many cases, passive and active machines can act as singular systems. They therefore do not necessarily require networking with other devices, machines and robots, nor additional services via a cloud. However, some already rely on additional human partners, such as the drone reporting the fawn. Proactive systems will often be a complex overall system with multiple components or an infrastructure with many elements (Mancini, 2021). The machines (especially robots) cooperate and collaborate so that they can handle tasks that are very demanding, such as moving heavy objects, numerous individual steps, or the specializations required (Bendel, 2021b). In a nature reserve, they could work together to remove obstacles and carcasses or go in search of a lost animal. Proactive machines could also benefit from a technical infrastructure, as indicated. In a nature reserve, cameras, microphones, and sensors of all kinds could be placed at feeding areas and elevated sites, and data from satellites could be incorporated, such as through the Global Positioning System
(GPS) or imagery from above. All of this data could then be tapped by the machines. Ground robots could be supplemented by aerial robots, which could traverse particularly rough terrain more quickly and possibly intervene more quickly in the event of danger. Human intervention is present in both semi-autonomous and autonomous machines. A control center that sees, hears, and smells with the help of the equipment and robots can take control of them or send a strike force if needed. Another option is to add ear tags, ear notches, tattoos, branding, RFID chips, and more powerful transmitters to the animals, making them identifiable and trackable by systems (or humans). Biotelemetry devices have also been common for a long time. However, their use can cause interference and injury (Paci et al., 2020).

\section{Animals and Humans as Interaction and Communication Partners}

Passive machines can target domestic, working, farm, and wild animals. Even laboratory animals, which have been left out in this review, are possible objects. Active and proactive machines are also possible solutions for all types of animals and animal species. By no means does this include only mammals or larger animals but also, for example, insects such as caterpillars, spiders, and beetles. Admittedly, depending on the type of animal and the species, very different modes of interaction and communication are possible and necessary (Mondada et al., 2013). It may simply be a matter of recognizing an animal and then halting operations, but it may also be a matter of specifically addressing the needs and capabilities of an animal species or even an individual animal. With regard to pets and farm animals, it will also be interesting to transfer human control and communication skills to the machines. Social robots, in particular, could play a similar role here in the future as normally responsible animals or humans, for example when they keep a herd together or give appropriate commands to a trained animal. Whereas, usually a service robot or a social robot interacts and communicates with a human, and animals often only join in by chance, here it is the other way around, which means, however, that the human must also be involved and perceived as a desired or undesired entity, as a person who may and should give commands, or who must be put in his place. In this context, cooperation and collaboration with other robots can be useful, for example with security robots in relation to a poacher.

\section{Ethical Considerations for These Types of Machines}

As more and more semi-autonomous and autonomous machines that can encounter animals proliferate, it seems appropriate to convert these machines into animal-friendly ones. Of course, from an ethical perspective, one can argue that the number of machines can and should be limited. This would avoid the suffering that can be caused by them. This is true, but out of scope in this review. Another objection may be that animals and machines should not share space for ethical, social, psychological, and medical reasons. There may well be animals and species that are stressed by the sight and behavior of machines and for whom contact with things is not enough. However, there 
are just as many, if not more, that are less stressed through contact with humans, and above all, it may be possible to avoid transferring our scent to the creatures, causing them to be rejected by their parents or herd, or causing the animals to become directly dependent on humans. Another objection may be that one already invades the intimacy and privacy of humans by passive, but especially by active and proactive machines. This can be granted to certain animals, such as non-human primates, at least in the sense that they sometimes want to be undisturbed. However, it seems unproblematic if the machines are not perceptible at all, which was one of several proposed options in this review. In particular, an infrastructure from which robots benefit can be implemented discreetly. Still, some caution is warranted with the machines themselves, because of their cameras and sensors and their physical presence alone. Moreover, humans can be bycatch, so to speak, if they are inadvertently captured by the cameras and sensors. As has been made clear time and again, machine ethics can also contribute. Here, the moral machines it designs and implements are animal-friendly in their nature. In addition to annotated decision trees, other approaches need to be developed.

\section{Economic Considerations for These Types of Machines}

Again and again, economic aspects have become clear in the preceding chapters and sections. The use of robots of all types can save costs for persons, groups, and institutions, provided that the costs for acquisition and operation are kept within limits and sufficient application possibilities exist. Thus, typical effects of automation arise. Some economic aspects are linked to technical and social utopias. When huge nature reserves are created in response to the destruction of nature and the loss of biodiversity, they can hardly be controlled by human labor, at least not at reasonable cost. Therefore, even and especially in the newly emerging wilderness-a possible response to crises and disasters-automation presents an opportunity. It would be necessary to create an overall system that consumes as few resources as possible. In the case of robots, especially proactive ones, self-sufficient energy supplies are conceivable and have already been tested, as in the case of the Energetically Autonomous Tactical Robot (EATR), a robot that can feed on plants (in principle, also, it is alleged, on corpses on the battlefield) (Bendel, 2017a). "Consumption" of organic material can not only provide necessary energy, but also contribute to forest management and livestock control. In addition, applications of artificial intelligence should be limited, especially with regard to resource-intensive machine learning.

\section{Robots as a Response to Crises and Disasters}

As was made clear in the sketch of two proactive machines, these can be of service in the event of crises and disasters, furthermore as a preventative response to crises and disasters, such as extensive nature reserves. In both cases, existing models and operational scenarios can be built upon-but further technical developments are needed, as well as societal, political, and legal frameworks. After all, it won't just be the case that semiautonomous or autonomous robots will rescue one animal after another without any problems or consequences. Rather, errors and accidents will occur, due to unsuitable algorithms as well as unforeseeable situations, and questions will be asked in individual cases as to why priority is given to animals and not to humans in times of need (although this need not be the case at all). Bendel (2021b) shows that also human enhancement could be a possible reaction to crises and catastrophes as well as the colonization of satellites and planets. These considerations could be transferred to animals. It must be considered that animal enhancement has so far been more to the detriment of animals (insofar as the benefit to humans was placed in the foreground) and that in the case of enhancements and implants, damage to health can also occur (Bendel, 2016b).

\section{SUMMARY AND FUTURE DIRECTIONS}

This paper has proposed a classification of machines to explore their actual and possible relationship to animals. Numerous examples of passive, active, and proactive machines have been identified. It is noticeable that these are in turn quite different, having divergent designs, tasks, and capabilities. This also depends on whether they are simple automata or (partially) autonomous robots. In the discussion, based on the systematization, considerations were given to automation status, moreover to another classification, namely that of service robots and social robots. The importance of the individual disciplines and their collaboration was emphasized, as well as that of creating overall systems, up to and including satellites. Lastly, the interaction and communication partners themselves, i.e., the animals and consequently humans, were addressed and the perspective of ethics was outlined.

Proactive machines seem to have considerable potential, at least if one takes economic considerations and technical or social utopias as a starting point. Human-centered AI could become nature-centered AI, social robotics could be understood not only as robotics for humans but also for animals (Bendel, 2021a) — in research and development, more and more attention could be paid to this blind spot, the concerns of animals in relation to machines, and in application, robots could be used to help both flora and fauna. Artificial intelligence admittedly raises difficulties, as machine learning and deep learning often require a lot of power. However, the applications outlined could be designed to conserve resources, and local applications are already sufficient for certain forms of facial recognition. Another conflict can again be identified with regard to resources: Each more complex machine and robot requires a variety of metals, rare earths, batteries or accumulators, etc., and social robots in particular, with their composite of metal and plastic, are difficult to dispose of. Overall, we are creating more and more artifacts that share space with us and that consume resources just like us.

Animal-computer interaction and animal-machine interaction need to continue to grow as disciplines, crossfertilizing machine ethics and social robotics as much as robotics 
as a whole and artificial intelligence. Animal ethicists, animal protectionists, and animal rights activists should perceive technology not only as a cause of problems and an enemy of living beings, but also as a possible solution, for all the criticism that needs to be made and all the progress that needs to happen. From increased interdisciplinarity, a transdisciplinary approach could one day emerge, under whatever name it is called. Animals and technology are becoming a more and more central, pressing issue, and a focus discipline on this area offers the chance to push humans away from the center of attention in research and development as well as application, and to make room for animals and plants, which we not only need for our survival, but which also have rights or values themselves. This shift in perspective is also important when we are still exploring the use of machines first and need to include animals in the process, or when the use itself is still a critical, provisional variant (Mancini, 2021).

This paper has outlined applications of all kinds that benefit animals (and in some cases plants). In many cases, these are

\section{REFERENCES}

Anderson, M., and Anderson, S. L. (2011). Machine Ethics. Cambridge: Cambridge University Press.

Bendel, O. (2013). Considerations about the relationship between animal and machine ethics. AI Soc. 31, 103-108. doi: 10.1007/s00146-013-0526-3

Bendel, O. (2014a). Advanced driver assistance systems and animals. Künstl. Intell. 28, 263-269. doi: 10.1007/s13218-014-0332-1

Bendel, O. (2014b). Wirtschaftliche und technische Implikationen der Maschinenethik. Die Betriebswirtsch. 4, 237-248.

Bendel, O. (2014c). Tierethik, in Gabler Wirtschaftslexikon. Wiesbaden: Springer Gabler. Available online at: https://wirtschaftslexikon.gabler.de/definition/ tierethik-54000 (accessed January 29, 2022)

Bendel, O. (2015). Überlegungen zur Disziplin der Tier-Maschine-Interaktion. gbs-schweiz.org. Available online at: https://gbs-schweiz.org/blog/ ueberlegungen-zur-disziplin-der-tier-maschine-interaktion/ (accessed February 14, 2015).

Bendel, O. (2016a). "Annotated decision trees for simple moral machines," in The 2016 AAAI Spring Symposium Series (Palo Alto, CA: AAAI Press), 195-201.

Bendel, O. (2016b). Animal Enhancement, in Gabler Wirtschaftslexikon. Wiesbaden: Springer Gabler. Available online at: https://wirtschaftslexikon. gabler.de/definition/animal-enhancement-54196 (accessed January 29, 2022)

Bendel, O. (2017a). Service Robots in Public Spaces. Telepolis. Available online at https://www.heise.de/tp/features/Service-Robots-in-Public-Spaces3754173.html (accessed June 25, 2017).

Bendel, O. (2017b). "LADYBIRD: the animal-friendly robot vacuum cleaner," in The 2017 AAAI Spring Symposium Series (Palo Alto, CA: AAAI Press), 2-6.

Bendel, O. (2019a). "Das LADYBIRD-Projekt," in Handbuch Maschinenethik, ed O. Bendel (Wiesbaden: Springer Gabler), 415-433.

Bendel, O. (2019b). 350 Keywords Digitalisierung. Wiesbaden: Springer Gabler.

Bendel, O. (2020). Der Einsatz von Servicerobotern bei Epidemien und Pandemien. HMD - Praxis der Wirtschaftsinformatik. Available online at: https:// link.springer.com/article/10.1365/s40702-020-00669-w (accessed October 14, 2020).

Bendel, O. (ed.). (2021a). Soziale Roboter: Technikwissenschaftliche, wirtschaftswissenschaftliche, philosophische, psychologische und soziologische Grundlagen. Wiesbaden: Springer Gabler.

Bendel, O. (2021b). "Chips, devices, and machines within humans: bodyhacking as movement, enhancement, and adaptation," in Mensch. Maschine. Kommunikation. Beiträge zur Medienlinguistik, eds S. Brommer and C. Dürscheid (Tübingen: Narr Francke Attempto), 252-276. Available online at: systems and machines that can already be used profitably and beneficially today. Particularly interesting, however, is the view of the future. Man is increasingly beset by crises and disasters, and some of these are due to industrialization, mechanization, and intensive agriculture. Mechanization, digitalization, and automation are part of the problem, but also part of the solution. They help exploit the earth on a large scale, but could, at the same time, help save animals in need and monitor and protect them in nature reserves. In the process, however, they themselves consume resources again, and they share space with humans and animals in certain areas, some of which is already heavily occupied and fragmented. Technical solutions of this kind can never be standalone but need social and political flanking measures. Ultimately, there are many methods to destroy the earth - and many to save it.

\section{AUTHOR CONTRIBUTIONS}

$\mathrm{OB}$ agrees to be accountable for the content of the work. https://elibrary.narr.digital/book/10.24053/9783823394716 (accessed January 29, 2022)

Bendel, O., Graf, E., and Bollier, K. (2021). "The HAPPY HEDGEHOG project," in Proceedings of the AAAI 2021 Spring Symposium "Machine Learning for Mobile Robot Navigation in the Wild" (Palo Alto, CA: Stanford University). Available online at: https://drive.google.com/file/d/ 1SvaRAI71wthGe-B9uSAYvL5WOzLI2mul/view (accessed January 29, 2022)

Brambilla, M., Ferrante, E., Birattari, M., and Dorigo, M. (2013). Swarm robotics: a review from the swarm engineering perspective. Swarm Intell. 7, 1-4. doi: 10.1007/s11721-012-0075-2

Christaller, T., Decker, M., and Gilsbach, J. (2001). Robotik: Perspektiven für menschliches Handeln in der zukünftigen Gesellschaft. Berlin; Heidelberg: Springer.

Deb, D., Wiper, S. M., Gong, S., and Shi, Y. (2018). "Face recognition: primates in the wild," in 2018 IEEE 9th International Conference on Biometrics Theory, Applications and Systems (BTAS) (Redondo Beach, CA), 1-10.

Ditmer, M. A., Vincent, J. B., Werden, L. K., Tanner, J. C., Laske, T. G., Iaizzi, P., et al. (2015). Bears show a physiological but limited behavioral response to unmanned aerial vehicles. Curr. Biol. 25, 2278-2283. doi: 10.1016/j.cub.2015.07.024

Fossgreen, A. (2017). Bei den Kühen piepts. Tages-Anzeiger. Available online at: https://www.tagesanzeiger.ch/wissen/bei-den-kuehen-piepts/story/26203583 (accessed September 9, 2017).

Harlow, H. F. (1959). Love in infant monkeys. Sci. Am. 200, 68-75.

Kurain, N. S., Poojasree, S., and Priyadharrshini, S. (2018). "Wildlife vehicle collision avoidance system," in SSRG International Journal of Electronics and Communication Engineering (SSRG - IJECE), Vol. 5 (Tennur).

Mancini, C. (2011). Animal-computer interaction (ACI): a manifesto. Interactions $18,69-73$.

Mancini, C. (2021). Animal-Computer Interaction: Auf dem Weg zum technologisch vermittelten Multispeziesismus [Animal-Computer Interaction: towards Technologically Mediated Multispeciesity]. Navigationen Zeitschrift für Medien- Kulturwissensch. 2021, 31-54. doi: 10.25819/ubsi/9913

May, R., Hamre, Ø., Vang, R., and Nygård, T. (2012). Evaluation of the DTBird Video-System at the Smøla Wind-Power Plant. Detection Capabilities for Capturing Near-Turbine Avian Behaviour. NINA Report 910.

Misselhorn, C. (2018). Grundfragen der Maschinenethik. Ditzingen: Reclam.

Mondada, F., Halloy, J., Martinoli, A., Siegwart, R., and Deneubourg, J. L. (2013). "A general methodology for the control of mixed natural-artificial societies," in Handbook of Collective Robotics: Fundamentals and Challenges, ed S. Kernbach (London: Taylor \& Francis), 547-586. 
Paci, P., Mancini, C., and Price, B. (2020). "Understanding the interaction between animals and wearables: the wearer experience of cats," in Proceedings of the International Conference on Designing Interactive Systems, ACM DIS2020 (ACM Press).

Pluta, W. (2017). Roboterwolf vertreibt Wildschweine. Golem. Available online at: https://www.golem.de/news/landwirtschaftroboterwolf-vertreibt-wildschweine-1708-129719.html (accessed August $28,2017)$.

Qin, M., Huang, Y., Stumph, E., Santos, L., and Scassellati, B. (2020). "Dog sit! Domestic dogs (Canis familiaris) follow a robot's sit commands," in HRI'20: Companion of the 2020 ACM/IEEE International Conference on Human-Robot Interaction (Cambridge), 16-24.

Schulze, H., Bendel, O., Schubert, M., Binswanger, M., Simmler, M., Reimer, R. T. D., et al. (2021). Roboter, Empathie und Emotionen. Bern: Zenodo. Available online at: https://zenodo.org/record/5554564 (accessed January 29, 2022)

Singer, P. (2009). Animal Liberation: The Definitive Classic of the Animal Movement. Updated Edition. New York, NY: HarperCollins.

Vincent, J. (2020). A Robot Sheepdog? 'No One Wants This,' Says One Shepherd. The Verge. Available online at: https://www.theverge.com/2020/5/22/21267379/ robot-dog-rocos-boston-dynamics-video-spot-shepherd-reaction (accessed May 22, 2020).

Wimmer, T., Israel, M., Haschberger, P., and Weimann, A. (2013). "Rehkitzrettung mit dem fliegenden Wildretter: Erfahrungen der ersten Feldeinsätze," in
Workshop Computer-Bildanalyse in der Landwirtschaft und 2. Workshop Unbemannte autonom fliegende Systeme (UAS) in der Landwirtschaft (Berlin), 85-95.

Yürekkirmaz, A. (2022). ANIFACE: animal-face-recognition (Bachelor thesis). School of Business FHNW, Olten, Switzerland.

Conflict of Interest: The author declares that the research was conducted in the absence of any commercial or financial relationships that could be construed as a potential conflict of interest.

Publisher's Note: All claims expressed in this article are solely those of the authors and do not necessarily represent those of their affiliated organizations, or those of the publisher, the editors and the reviewers. Any product that may be evaluated in this article, or claim that may be made by its manufacturer, is not guaranteed or endorsed by the publisher.

Copyright (c) 2022 Bendel. This is an open-access article distributed under the terms of the Creative Commons Attribution License (CC BY). The use, distribution or reproduction in other forums is permitted, provided the original author(s) and the copyright owner(s) are credited and that the original publication in this journal is cited, in accordance with accepted academic practice. No use, distribution or reproduction is permitted which does not comply with these terms. 